Published in "Behavioural Brain Research 359(): 104-115, 2019"

which should be cited to refer to this work.

\title{
Dopamine transporter (DAT) knockdown in the nucleus accumbens improves anxiety- and depression-related behaviors in adult mice
}

\author{
Amine Bahi ${ }^{\mathrm{a}, *}$, Jean-Luc Dreyer ${ }^{\mathrm{b}}$ \\ ${ }^{a}$ Department of Anatomy, Tawam Medical Campus, United Arab Emirates University, Al Ain, United Arab Emirates \\ ${ }^{\mathrm{b}}$ Division of Biochemistry, Department of Medicine, University of Fribourg, CH-1700 Fribourg, Switzerland
}

Many epidemiological and clinical studies have demonstrated a strong comorbidity between anxiety and depression, and a number of experimental studies indicates that the dopamine transporter (DAT) is involved in the pathophysiology of anxiety and depression. However, studies using laboratory animals have yielded inconclusive results. The aim of the present study was to examine the effects of DAT manipulation on anxiety- and depression-like behaviors in mice. For this purpose, animals were stereotaxically injected with DAT siRNAexpressing lentiviral vectors (siDAT) in the caudate putamen $(\mathrm{CPu})$ or in the nucleus accumbens (Nacc) and the behavioral outcomes were assessed using the open-field (OF), elevated-plus maze (EPM), light-dark box (LDB), sucrose preference (SPT), novelty suppressed feeding (NSF), and forced-swim (FST) tests. The results showed that in the Nacc, but not in the $\mathrm{CPu}$, siDAT increased the time spent at the center of the arena and decreased the number of fecal boli in the OF test. In the EPM and LDB tests, Nacc siDAT injection increased the entries and time spent on open arms, and increased the time spent in the light side of the box, respectively, suggesting an anxiolytic-like activity. In addition, siDAT, in the Nacc, induced significant antidepressant-like effects, evidenced by increased sucrose preference, shorter latency to feed in the NSF test, and decreased immobility time in the FST. Most importantly, Pearson's test clearly showed significant correlations between DAT mRNA in the Nacc with anxiety and depression parameters. Overall, these results suggest that low DAT levels, in the Nacc, might act as protective factors against anxiety and depression. Therefore, targeting DAT activity might be a very attractive approach to tackle affective disorders.

\section{Introduction}

According to the World Health Organization, the proportion of the global population with anxiety and depression in 2015 was estimated to be 3.6 and $4.4 \%$ respectively [1]. In addition, the total estimated number of people living with anxiety and depression increased by $14.9 \%$ and $18.4 \%$ respectively between 2005 and 2015, as a result of population growth and ageing [2]. Although generalized anxiety and major depressive disorders (GAD and MDD respectively) are associated with high disease burden, the molecular mechanisms involved in these psychiatric disorders are not fully understood. Therefore, elucidating the precise nature of these comorbidities could help understanding the pathophysiology of anxiety- and depression-related disorders.

The dopaminergic system plays a crucial role in both the periphery and the central nervous system (CNS). Centrally, dopamine is a neurotransmitter distributed in the brain stem in pons and medulla oblongata [3] as well as in the forebrain (covering hippocampus, amygdala, nucleus accumbens, putamen, and caudate) [4]. It regulates emotional and behavioral conditions along with other neurotransmitters. In fact, in patients with GAD and MDD, neuroreceptor imaging and anatomical/pharmacological studies showed abnormal central dopamine function $[5,6]$. For example, using SPECT neuroreceptor imaging, Tiihonen and co-workers found, when measuring striatal presynaptic dopaminergic innervation, that DAT binding was significantly lower in the patients with social anxiety disorder than in the age- and gender-matched comparison subjects [7]. Furthermore, when subjects with generalized social phobia, according to the DSM-IV, were tested using a fMRI study while executing the implicit sequence

Abbreviations: $\mathrm{CPu}$, caudate putamen; DAT, dopamine transporter; EPM, elevated-plus maze; FST, forced-swim test; LDB, light-dark box; LV, lentiviral vectors; NSF, novelty supressed feeding; Nacc, nucleus accumbens; OF, open-field; shRNA, short herpin RNA; siRNA, small interfering RNA; SPT, sucrose preference test; SNc, substantia nigra pars compacta; TST, tail suspension test; VTA, ventral tegmental area

* Corresponding author.

E-mail address: amine.bahi@gmail.com (A. Bahi). 
learning task, results have shown significant striatal abnormalities especially in the left caudate head, left inferior parietal lobe, and bilateral insula [8].

The dopamine transporter (DAT) is involved in the transport of dopamine, either into or out of the neuron, to control its levels at the synapse. Indeed, in the dorsal striatum and Nacc, it has been shown that the removal of dopamine from the synapse is predominantly performed by the neuronal DAT and not metabolism or diffusion [9]. However, in the prefrontal cortex (PFC), it's important to clarify that the norepinephrine transporter (NET) is present in much greater concentrations than DAT. Thus, dopamine uptake in the PFC is thought to depend primarily on NET [10].

The rat DAT cDNA, encoding a protein of 620 amino acid, was cloned more than 25 years ago. The analysis of the protein sequence suggested the presence of twelve putative transmembrane domains [11]. Apart from the five intracellular and six extracellular loops, DAT exhibits a cytoplasmic amino and carboxyl-termini that were shown to interact with the $\mathrm{Ca}^{2+} /$ calmodulin-dependent protein kinase II (CaMKII) to regulate the efflux of dopamine through DAT. In fact, CaMKII $\alpha$ binds to the distal carboxyl-terminal of DAT and colocalize with DAT in dopaminergic neurons [12]. DAT is a target for the development of pharmacotherapies for a number of disorders including Parkinson's disease [13], Alzheimer's disease [14], schizophrenia [15], Tourette's syndrome [16], Lesch-Nyhan's disease [17], attention deficit hyperactivity disorder [18], obesity [19], depression [20], and stimulant abuse [21] as well as normal aging [22]. Therefore, and because DAT can influence the re-uptake of dopamine, we suggest that it may have a role in the pathophysiological mechanisms of anxiety and depression-like behaviors.

Although the exact mechanisms by which DAT affects dopaminemediated neurotransmission in anxiety- and depression-like behaviors remain to be fully defined, previous studies have provided evidence that DAT might be involved in the pathophysiology of mood disorders. For example, neuroimaging studies suggested a dysfunction of the striatal presynaptic DAT in social anxiety disorder [23]. Also, PET imaging revealed a significant reduction in DAT binding potential (BP) in the striatum of unmedicated patients with MDD [24], and decreased $\mathrm{BP}$ in the caudate, but not the putamen of patients relative to healthy controls [25].Therefore, understanding these processes will not only help elucidate the complex mechanisms of anxiety and depression comorbidities, but also help in the development of effective therapies to counteract these disorders.

Although a previous study showed that DAT over-expression in adult Wistar rats' Nacc leads to impulsive and risk prone phenotype [26], and rats with intra-accumbal delivery of DAT shRNA-expressing lentiviral vectors, showed a trend, $(0.05<p<0.10)$ toward an anxiogenic-like phenotype [27], few experimental studies have directly and systematically examined the role of DAT in anxiety and depression, and little is known about the specific contribution of accumbal DAT. In fact, there is evidence that emotional disorders such as anxiety and depression are associated with increased impulsivity [28-31]. However, other studies revealed that reduced anxiety- and depression-related responses correlated with increased impulsivity [32,33]. Therefore, the current experiments were designed to test the hypothesis that DAT knockdown in the Nacc can elicit dysregulated behaviors in adult C57BL/6 mice, including anxiety- and depressive-like symptoms. In first, we choose a battery of the most commonly used tests (OF, EPM and LDB) to study the effects of DAT knock-down on anxiety-like behavior. The second goal was to examine the consequences of DAT knock-down on depression-like behavior in adult C57BL/6 mice using the SPT, NSFT, and FST. We hypothesized that DAT knock-down in the Nacc will ameliorate anxiety-like behaviors, and consequently DAT anxiolytic prone phenotype will be associated to an antidepressant-like activity.

\section{Materials \& methods}

\subsection{Animals}

C57BL/6 J mice were originally obtained from Jackson Laboratory (Bar Harbor, ME) and bred in the local animal facility of the College of Medicine \& Health Sciences of the UAE university. All mice were of identical genetic background and back-crossed to the parental inbreed mice each ten generations. For the current study, adult male C57BL/6 J (approximately 22-26 g) were maintained in a temperature-controlled $\left(\sim 22^{\circ} \mathrm{C}\right)$ colony room with a 12 -hour light-dark cycle (0600 to 1800 light on). A large number of published reports used the same lighting conditions with the housing room kept under a regular light/dark schedule $[34,35]$. The mice (44 in total) were group-housed until they underwent the stereotaxic injections yielding 4 experimental groups ( $n=11$ each). Mice were singly housed after the surgery, and during subsequent behavioral testing to minimize confounding effects of group housing and establishment of social hierarchies [36]. Bedding was produced locally and autoclaved before use. Water and food were available ad libitum throughout the experiment. Standard rodents' chow diet was obtained from the National Feed and Flour Production and Marketing Company LLC (Abu Dhabi, UAE). The local Animal Research Ethics Committee approved the procedures (Application Reference No. A27-12).

\subsection{Design and cloning of small hairpin RNAs and lentivirus production}

Plasmid construction was described in previously published work from our laboratory [26,27,37]. In brief, the following target within DAT sequence 5'-AGC CAT GGA TGG CAT CAG AGC ATA CCT-3' was selected based on Hannon's design criterion (http://katahdin.cshl.org: 9331/RNAi/html/rnai.html). The sequence was subjected to a BLAST search to verify its specificity and the pairwise sequence similarity search yielded a $96 \%$ homology between mouse and rat sequences. A stem-loop structure incorporating the nucleotides' target sequence was created so that small hairpin RNAs (shRNAs) could be produced from the lentiviral vector pTK431 (graciously provided by Dr. Tal Kafri, UNC Gene Therapy Center). The siRNA target was synthesized and added to the mouse U6 promoter by PCR, using following PCR program: $120 \mathrm{~s}$ at $94{ }^{\circ} \mathrm{C}$ (initial denaturation) followed by 35 cycles $\left(45 \mathrm{~s}\right.$ at $94^{\circ} \mathrm{C}, 45 \mathrm{~s}$ at $64{ }^{\circ} \mathrm{C}$ and $45 \mathrm{~s}$ at $72{ }^{\circ} \mathrm{C}$ ) in $4 \%$ dimethyl sulfoxide (DMSO). The PCR product was digested with BamHI and XhoI, cloned into similar sites into pTK431. The control vector (Mock) consisted of an empty pTK431.

For lentiviral production, a triple transfection protocol was used as described previously [38-40]. Briefly, the pTK431-transfer plasmids together with the packaging $\mathrm{p} \Delta \mathrm{NRF}$ and the envelope pMDG-VSV-G plasmids were co-transfected into HEK293 T cells using calcium phosphate. Medium was collected at 24 and $48 \mathrm{~h}$ post-transfection and virus concentrated by centrifugation. The supernatant was removed, and virus was suspended in sterile cold phosphate-buffered saline (PBS) supplemented with $1 \%$ bovine serum albumin (BSA). Viral titers (approximately $10^{8}-10^{9}$ unit/mL) were determined using a p24 antigen ELISA kit.

\subsection{Stereotaxic injection of lentiviral vectors}

For viral injection, mice were first anesthetized with a cocktail of ketamine (100 mg/kg, i.p.) and xylazine $(10 \mathrm{mg} / \mathrm{kg}$, i.p.) and placed in a stereotaxic frame. Using ear bars, the head was fixed, and a midline incision was made to measure the bregma from the skull surface. A craniotomy was drilled, and a Hamilton micro-syringe filled with a viral solution was lowered using the following coordinates for the Nacc $[+1.7 \mathrm{~mm} \mathrm{AP}, \pm 0.75 \mathrm{~mm} \mathrm{ML}$, and $4.5 \mathrm{~mm}$ ventral from the dural surface]. Because the $\mathrm{CPu}$ is part of the dorsal striatum and is significantly large and functionally heterotopic, two separate injections were performed in each hemisphere using the following coordinates: 
[1 ${ }^{\text {st }}$ injection: $+1 \mathrm{~mm} \mathrm{AP,} \pm 1.5 \mathrm{~mm} \mathrm{ML}$, and $3.5 \mathrm{~mm}$ ventral $],\left[2^{\text {nd }}\right.$ injection: $-0.10 \mathrm{~mm} \mathrm{AP}, \pm 2.5 \mathrm{~mm} \mathrm{ML}$, and $3.8 \mathrm{~mm} \mathrm{DV}$ ] [41-44]. For each injection, $0.5 \mu \mathrm{L}$ of viral particles were infused at a rate of $0.1 \mu \mathrm{L} /$ min. Following vector administration, the Hamilton micro-syringe was left in situ for an additional $5 \mathrm{~min}$ to permit time for the vector to diffuse from the needle tip and minimize upward flow of viral solution after raising the needle before being slowly retracted from the brain. The skin was stitched, and mice were monitored until recovery from the surgery before returned to their home cage and left to recover 10 days before behavioral experiments started to ensure good levels of expression. None of the injected animals were excluded from the statistical analysis.

\subsection{Anxiety- and depression-related behavior tests}

All anxiety-like behavior tests were conducted between 10:00 AM and 4:00 PM in a brightly lit room that was illuminated with four fluorescent overhead bulb lights, which produce consistent illumination within the room (approximately $100 \mathrm{~lx}$ ). The mice were habituated to the room for $1 \mathrm{~h}$ before starting the respective test. The general design of the study is depicted in Supp. Fig. 1.

\subsubsection{Open-field (OF)}

10 days following viral injection, spontaneous and exploratory locomotor activity and anxiety were tested in an OF test as reported in our previous studies [45-47]. In brief, each mouse was placed in the corner of the OF apparatus $\left(32 \times 32 \times 20 \mathrm{~cm}^{3}\right)(\mathrm{L} \times \mathrm{W} \times \mathrm{H})$ and allowed to freely explore the arena for $15 \mathrm{~min}$. The time spent in the center of the arena $\left(8 \times 8 \mathrm{~cm}^{2}\right)$, the number of line crossings, and the number of fecal boli were hand scored. After each session, fecal boli were counted and removed, and the arena was cleaned with a 70\% pure ethanol solution to remove odor trails.

\subsubsection{Elevated-plus maze (EPM)}

This test is an ethologically relevant assessment of anxiety levels in rodents [48]. Two days after the OF test, animals were tested in the EPM as previously performed in our laboratory $[47,49,50]$. The EPM apparatus consisted of two open arms (OA) $\left(40 \times 6 \mathrm{~cm}^{2}\right)$ and two closed arms (CA) $\left(40 \times 6 \times 20 \mathrm{~cm}^{3}\right)$, connected by a central platform $\left(6 \times 6 \mathrm{~cm}^{2}\right)$ and elevated $40 \mathrm{~cm}$ off the floor. Although, differences were observed when rodents were placed facing toward an OA versus toward the CA [48], at the beginning of the session each mouse was placed into the center of the maze, facing one of the OA and behavior was monitored live for $5 \mathrm{~min}$ as described by others [51,52]. The number of entries and the time spent in each arm of the maze were hand scored. After each EPM testing, animals were immediately returned to their home cages, and the maze was cleaned with a $70 \%$ pure ethanol solution to remove odor trails.

\subsubsection{Light-dark box (LDB)}

The original method described by [53] was used with minor modifications as in our recent study [46]. In brief, the apparatus consisted of two wood chambers $\left(24 \times 30 \times 30 \mathrm{~cm}^{3}\right)$ connected by a 6 - $\mathrm{cm}$ wide guillotine door. One chamber had black walls covered by the lid, and the other had white walls with a $60 \mathrm{~W}$ light bulb located $30 \mathrm{~cm}$ above the chamber. For the experiment, each mouse was placed in the light chamber and could explore the two chambers for 5 min as described by others [54-56]. The following parameters were hand scored: $i$ ) latency to enter the dark chamber (sec), ii) latency to re-enter the light chamber (sec), iii) total time spent in the light chamber (sec), and iv) number of crossings/transitions between the two chambers (n). The two chambers were cleaned with $70 \%$ ethyl alcohol and dried between trials.

\subsubsection{Sucrose preference test (SPT)}

The SPT was performed as described previously [57]. Briefly, a twobottle choice procedure was used to test for differences between the groups for their relative preference for sucrose over water. The mice were given free choice access to 2 pipettes: one containing tap water and the other containing a $2 \%$ sucrose-solution for $24 \mathrm{~h}$. The pipettes were switched (left/right) after $12 \mathrm{~h}$ to eliminate side preference. We monitored the latency to initiate drinking, and the amount of water and sucrose consumed in milliliters during the $24 \mathrm{~h}$ was measured and the percent preference for sucrose consumption was calculated as a percentage of sucrose solution consumed in relation to the total fluid intake. The total fluid intake (water + sucrose) was measured and expressed in milliliters per kilogram of body weight.

\subsubsection{Novelty suppressed feeding test (NSFT)}

The NSFT was performed as described previously [57]. In brief, $24 \mathrm{~h}$ before the test all the mice were food deprived. The novel environment consisted of a Plexiglas cage $\left(45 \times 28 \times 13 \mathrm{~cm}^{3}\right)$ brightly lit using a $60 \mathrm{~W}$ light bulb located $50 \mathrm{~cm}$ above the cage lid, directly above the food dish. The food dish was a $5 \mathrm{~cm}$-diameter filter paper containing a previously weighed piece of standard lab chow. Each mouse was placed into the novel cage for $15 \mathrm{~min}$ and the following parameters were hand scored: $i$ ) latency to begin eating (defined as chewing of food), ii) total time spent eating in the test box, iii) amount of food consumed in the test box. At the end of each session, the mouse was immediately returned to its home cage and, as a control, food consumption was assessed by weighing each cage's food at the beginning and end of a 24-h period.

\subsubsection{Forced-swim test (FST)}

The FST originally described by Porsolt and co-workers [58] was performed as we described in our previous studies [47,59]. Although, the FST for mice consists of a single 6-min exposure, some investigators have developed two session procedures as well [60]. In the current study, each mouse was individually forced to swim in a 1-liter glass beaker (Height: $158 \mathrm{~mm}$; Width: $108 \mathrm{~mm}$ ) containing water at a temperature of approximately $25^{\circ} \mathrm{C}$ for $6 \mathrm{~min}$ as described by others [61-64]. The mice were unable to escape or rest by touching the bottom of the beaker. The time taken by the animal to start struggling and swimming (latency time) as well as the duration of immobility were hand scored. After each trial, the water was changed.

\subsection{Total RNA isolation and quantitative RT-PCR analysis}

After the completion of behavioral testing, the mice were killed by rapid decapitation. The brains were quickly removed, Nacc and $\mathrm{CPu}$ samples (used as a control region) were dissected out and stored at $-80^{\circ} \mathrm{C}$. Total RNA was extracted using the TRIzol reagent and precipitated with isopropanol according to the manufacturer instructions. To verify DAT mRNA (Accession No. NM_012694) knockdown, singlestranded cDNA was synthesized from total RNA using the SuperScript III reverse transcriptase procedure. Following reverse transcription, quantitative RT-PCR was performed in triplicate using SyberGreen purchased from Applied Biosystems, per the manufacturer instructions. The temperature cycling parameters consisted of initial denaturation at $95^{\circ} \mathrm{C}$ for $4 \mathrm{~min}$ followed by 40 cycles of denaturation at $94^{\circ} \mathrm{C}$ for $30 \mathrm{~s}$, annealing and extension at $60^{\circ} \mathrm{C}$ for $45 \mathrm{~s}$. PCR for the endogenous housekeeping gene, cyclophilin, was run with the same cycling parameters. The template $(2 \mu \mathrm{l})$ was amplified by PCR in $20 \mu \mathrm{l}$ total reaction volume containing $0.5 \mu \mathrm{mol}$ of each specific PCR primer. Gene expression levels were analyzed by the $\Delta \Delta \mathrm{Ct}$ method using cyclophilin as a reference gene because of its low variability between samples.

\subsection{Statistical analyses}

For statistical comparisons, the software package IBM SPSS Statistics 16.0 was used. Data were expressed as means \pm SEM. The data representing the effects of DAT knockdown on anxiety- and depression-like behaviors were analyzed using a two-way analysis of 
variance (ANOVA) with viral-injection "Mock $v s$. siDAT" and brain region "Nacc vs. CPu" as the between-subject factors. Simple linear regression (Pearson's test) analysis was performed to examine the correlation between DAT mRNA levels in the CPu or the Nacc and measures of anxiety- and depression-like behaviors. The relationship is expressed as the correlation coefficient (r). Levene's test was used to inspect the homogeneity of variance of all data. The acceptable level of significance was $5 \%$ for each analysis.

\section{Results}

\section{1. siDAT injection reduced DAT mRNA in the Nacc and CPu}

To knock-down DAT expression, we expressed DAT siRNAs (siDAT) using a lentiviral vector that was stereotaxically injected into the Nacc or into the $\mathrm{CPu}$ (used as a control region), of adult mice (for each group, $\mathrm{n}=11$ ).

To determine the persistence of infection in the Nacc and $\mathrm{CPu}$, mice were injected bilaterally with siDAT and examined for mRNA expression after completion of the behavioral experiment. In fact, to determine the efficacy of siDAT, we measured levels of DAT mRNA, using RT-PCR, of infected Nacc and CPu, tissues and the results are summarized in Table 1. The two-way ANOVA revealed a significant effect of viral-injection $\left(\mathrm{F}_{(1,40)}=254.713, p<0.0001\right)$. However, and as expected there was no significant effect of brain region $\left(F_{(1,40)}=0.271\right.$, $p=0.605)$, and the interaction between the two factors was not found significant $\left(\mathrm{F}_{(1,40)}=0.263, p=0.611\right)$. Bonferroni post hoc evaluations indicated that, regardless of the brain region, DAT mRNA levels were decreased by approximately $70 \%$, indicating that the siDAT was functional. We also measured DAT mRNA expression in both areas for vector inoculated in either area, and the results are depicted in Table 1. The two-way ANOVA revealed no effect of viral-injection $\left(\mathrm{F}_{(1,40)}=0.051, p=0.822\right)$, or brain region $\left(\mathrm{F}_{(1,40)}=1.125, p=\right.$ $0.295)$, with no significant interaction $\left(\mathrm{F}_{(1,40)}=1.056, p=0.310\right)$, clearly indicating that the injections were site specific and mRNA expression alterations could be found in a non-targeted region. Thus, the effects were limited to the region of the injection. Taken together, these results suggested that we could consistently infect both the $\mathrm{CPu}$ and Nacc, the infection lasted for the time required to complete behavioral experiments, and siDAT were effective in downregulating DAT expression in infected neurons in vivo.

\subsection{DAT knockdown in the Nacc altered anxiety-like behavior}

\subsubsection{Open-field (OF)}

We first tested the mice in an OF test that was performed 10 days after viral injections as depicted in Suppl. Fig. 1. During this assay, in which the effects of stimulation on spontaneous behaviors could be characterized, the Levene's test for equality of variances was found to be statistically non-significant $\left(\mathrm{F}_{(3,40)}=0.930, p=0.435\right)$. Therefore, and as depicted in Fig. 1A, the two-way ANOVA test revealed a

Table 1

DAT mRNA expression in Mock- and siDAT-injected mice.

\begin{tabular}{llll}
\hline Injection site & mRNA level in & Mock & siDAT \\
\hline $\mathrm{CPu}$ & $\mathrm{CPu}$ & $1.000 \pm 0.176$ & $0.322 \pm 0.105^{*, \#}$ \\
& $\mathrm{Nacc}$ & $1.000 \pm 0.157$ & $1.072 \pm 0.221$ \\
$\mathrm{Nacc}$ & $\mathrm{CPu}$ & $1.000 \pm 0.182$ & $0.951 \pm 0.202$ \\
& $\mathrm{Nacc}$ & $1.000 \pm 0.191$ & $0.277 \pm 0.079$,\# \\
\hline
\end{tabular}

The data are expressed as mean \pm SEM for the relative mRNA expression in the Nacc and $\mathrm{CPu}$ with or without lentiviral injection.

$* p<0.0001$ indicate significant differences between Mock- and siDAT (Injection site).

${ }_{\#} p<0.0001$ indicate significant differences between Nacc and the $\mathrm{CPu}$. For each group $\mathrm{n}=11$. significant effect of viral-injection $\left(\mathrm{F}_{(1,40)}=8.925, p=0.005\right)$, and brain region $\left(\mathrm{F}_{(1,40)}=4.212, p=0.047\right)$. Interestingly, the interaction between the two factors was also found significant $\left(F_{(1,40)}=7.509\right.$, $p=0.009$ ). Bonferroni post hoc evaluations indicated that, compared to Mock controls, lentiviral-mediated knockdown of DAT (siDAT) in the Nacc, but not in the $\mathrm{CPu}$, increased the time spent in the center of the arena ( $p=0.001$ and $p=1.000$ respectively). These findings indicate that siDAT-injected mice in the Nacc show less aversion than Mock controls to the center of the $\mathrm{OF}$, which is consistent with decreased anxiety-like behavior. Also, and as depicted in Fig. 1B, the Levene's test was not significant $\left(\mathrm{F}_{(3,40)}=0.558, p=0.646\right)$ for the number of fecal boli. However, the two-way analysis indicated that there was a significant effect of viral-injection $\left(\mathrm{F}_{(1,40)}=10.851, p=0.002\right)$, and brain region $\left(\mathrm{F}_{(1,40)}=8.756, p=0.005\right)$ on the number of fecal boli left in the arena with a significant interaction $\left(\mathrm{F}_{(1,40)}=10.128, p=\right.$ 0.003). Pairwise evaluations revealed that, compared to Mock controls, siDAT injections in the Nacc, but not in the $\mathrm{CPu}$, significantly decreased the number of fecal boli ( $p<0.0001$ and $p=1.000$ respectively). Finally, to verify whether DAT manipulation in the Nacc influenced spontaneous exploratory behavior, which may influence the performance on the OF test, general locomotor activity was determined over the 15-min test. The statistical analysis indicated that the number of line crossings did not differ significantly between the four experimental groups as the main effect of viral-injection $\left(\mathrm{F}_{(1,40)}=0.0001, p=\right.$ $0.991)$ and brain region $\left(\mathrm{F}_{(1,40)}=0.107, p=0.746\right)$ were not found significant. Consequently the viral-injection $\times$ brain interaction was not significant $\left(\mathrm{F}_{(1,40)}=0.526, p=0.473\right)$ (Levene's test: $\left(F_{(3,40)}=0.812, p=0.495\right)$ (Fig. 1C) suggesting that the potential anxiolytic effect of DAT knockdown in the Nacc, observed in the OF test was not confounded by changes or deficits in overall spontaneous motor activity.

\subsubsection{Elevated-plus maze (EPM)}

Two days after the OF test, the mice were tested in the EPM test which exploits the conflict between the desire to explore a novel area and aversion to open areas and height [65]. For the percentage of time spent into the open arms (OA), the two-way ANOVA revealed a significant effect of viral injection $\left(\mathrm{F}_{(1,40)}=6.405, p=0.015\right)$, and brain region $\left(\mathrm{F}_{(1,40)}=7.240, p=0.010\right)$, with significant interaction $\left(\mathrm{F}_{(1,40)}=8.242, p=0.007\right)$ (Levene's test: $\left.\mathrm{F}_{(3,40)}=1.503, p=0.229\right)$ (Fig. 1D). Post hoc evaluations indicated that siDAT-injected mice in the Nacc, but not in the $\mathrm{CPu}$, spent more time in the OA of the maze than Mock controls ( $p=0.003$ and $p=1.000$ respectively). Similarly, there was a significant effect of viral injection $\left(\mathrm{F}_{(1,40)}=10.295, p=0.003\right)$, and brain region $\left(\mathrm{F}_{(1,40)}=9.573, p=0.004\right)$ on the number of entries into the OA with a statistically significant interaction $\left(\mathrm{F}_{(1,40)}=8.877\right.$, $p=0.005$ ) (Levene's test: $\left.\mathrm{F}_{(3,40)}=0.843, p=0.479\right)$. Post hoc tests indicated that the number of entries into the OA was significantly increased in Nacc mice injected with siDAT compared to Mock ( $p=$ 0.001). However, in the $\mathrm{CPu}$ group, there was no difference between Mock and siDAT conditions ( $p=1.000$, Bonferroni post hoc test) (Fig. 1E). Significant differences between the $\mathrm{CPu}$ and Nacc groups were revealed when OA entries were expressed as a percentage of total entries to account for differences in locomotion (main effect of brain region: $\left.F_{(1,40)}=4.613, p=0.038\right)$. siDAT injection in the Nacc significantly increased the percentage of $\mathrm{OA}$ entries (main effect of viralinjection: $F_{(1,40)}=9.346, p=0.004$ ) yielding significant interaction between the two factors $\left(\mathrm{F}_{(1,40)}=5.311, p=0.026\right)$ (Levene's test: $\mathrm{F}_{(3,40)}=0.857, p=0.471$ ) (Data not shown). It should be mentioned that the siDAT effects on the parameters measured in the EPM test were mainly driven by the Nacc group, which differentially and significantly affected the Mock- and siDAT-injected mice $(p=0.001$, Bonferroni post hoc test) (Data not shown). The overall activity was estimated by the number of entries performed into the closed arms (CA) during the 5-min observation period. Interestingly, as depicted in Fig. $1 \mathrm{~F}$ this parameter was not affected by viral-injection $\left(\mathrm{F}_{(1,40)}=0.963, p=0.332\right)$, nor by 
A

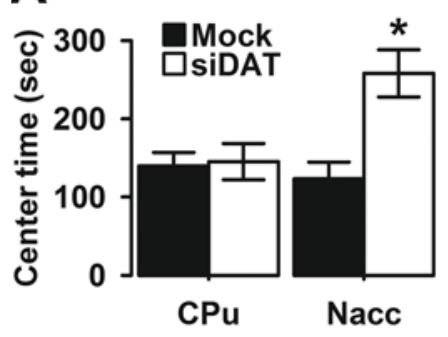

B

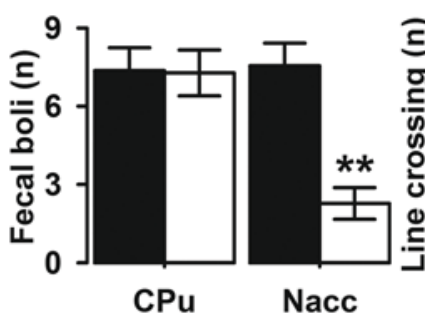

C

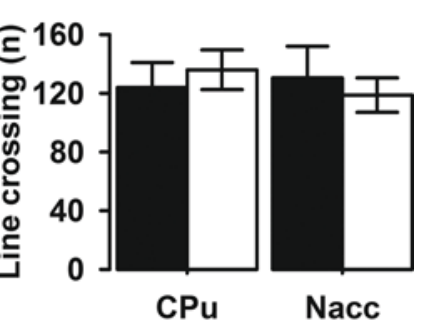

Fig. 1. Anxiety-like behavior in Mock- and siDAT-injected mice in the OF and EPM tests. The data are expressed as mean \pm SEM for the A) time spent in the center of the arena, B) number of fecal boli, C) number of line crossings in the OF test, D) percentage of time spent in open arms (OA), E) number of entries into the $\mathrm{OA}$, and F) number of entries into the closed arms (CA) of the EPM. * $p<0.005$, and $* * p<0.001$ indicate significant differences between Mock- and siDAT-injected mice in the Nacc. For each group $\mathrm{n}=11$.

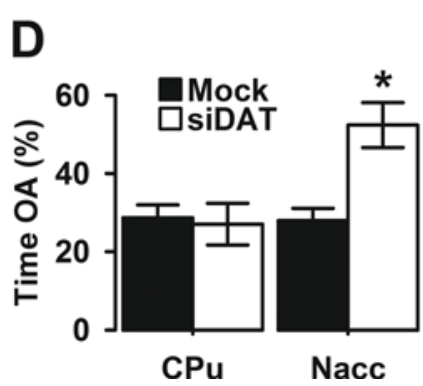

E

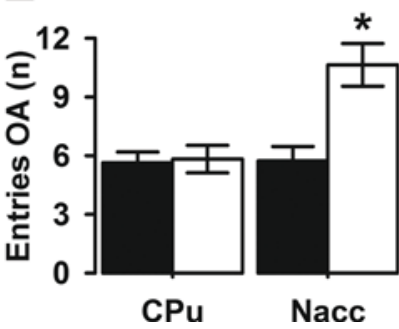

$\mathbf{F}$

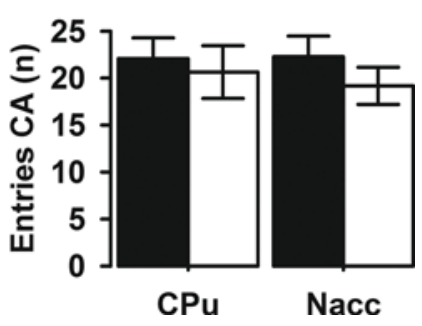

brain region $\left(\mathrm{F}_{(1,40)}=0.076, p=0.785\right)$, with no significant interaction $\left(\mathrm{F}_{(1,40)}=0.125, p=0.726\right)$ (Levene's test: $\mathrm{F}_{(3,40)}=0.082, p=$ 0.969 ) indicating no change in overall ambulatory behavior during the EPM test. These findings further indicate that lower levels of DAT in the Nacc reduced anxiety-like behavior.

\subsubsection{Light-dark box (LDB)}

Next, we assessed anxiety-like behavior using a LDB test, which examines the conflict between the drive to explore and aversion to a brightly lit space. The two-way ANOVA revealed that the latency for the mice to make the first move to the dark box was significantly affected by viral-injection $\left(\mathrm{F}_{(1,40)}=4.786, p=0.035\right)$, and brain region $\left(\mathrm{F}_{(1,40)}=5.403, p=0.025\right)$, with a significant interaction between the two factors $\left(\mathrm{F}_{(1,40)}=5.090, p=0.030\right)$ (Levene's test: $\mathrm{F}_{(3,40)}=2.175$, $p=0.106$ ) (Fig. 2A). Post hoc tests indicated that when injected in the Nacc, siDAT-injected mice showed a significantly increased latency to enter the dark side of the box compared to the Mock controls $(p=$ 0.019). However, and as depicted in Fig. 2B, once they have entered the dark box, siDAT-injected mice displayed a significantly shorter latency to re-enter the light box; main effect of viral-injection: $\left(\mathrm{F}_{(1,40)}=8.860\right.$, $p=0.005)$, main effect of brain region $\left(\mathrm{F}_{(1,40)}=10.486, p=0.002\right)$, interaction $\left(\mathrm{F}_{(1,40)}=12.021, \quad p=0.001\right)$ (Levene's test: $\left.\mathrm{F}_{(3,40)}=1.495, p=0.231\right)$. Although there was a main effect of brain region across both groups, Bonferroni post hoc tests revealed that this effect was driven by the Nacc group. In fact, the latency to re-enter the light box was significantly lower in Nacc siDAT-injected mice compared to Mock controls $(p<0.0001)$. In contrast, no significant differences were found in the CPu group between Mock-and siDAT-injected mice $(p=1.000)$. In addition, there were main effects of viral-injection $\left(\mathrm{F}_{(1,40)}=6.464, p=0.015\right)$ and brain region $\left(\mathrm{F}_{(1,40)}=5.618, p=\right.$ $0.023)$ on time spent in the light side of the chamber. Also, there was a significant interaction between the two variables $\left(\mathrm{F}_{(1,40)}=7.535, p=\right.$ 0.009) (Levene's test: $\mathrm{F}_{(3,40)}=1.050, p=0.381$ ) (Fig. 2C). Bonferroni post hoc tests revealed that the only comparison which differed significantly was in the Nacc group in which siDAT-injected mice spent more time in the light side of the box compared with Mock controls $(p=0.003)$. These findings further indicate that anxiety-like behavior is reduced in Nacc siDAT-injected mice. Interestingly, there was no significant effect of viral-injection $\left(\mathrm{F}_{(1,40)}=0.044, p=0.836\right)$, brain region $\left(\mathrm{F}_{(1,40)}=0.006, p=0.939\right)$ or an interaction of the independent variables $\left(\mathrm{F}_{(1,40)}=0.245, p=0.623\right)$ in the number of crossings/ transitions between light and dark sides of the box, again confirming that locomotor activity is similar in both groups (Levene's test:
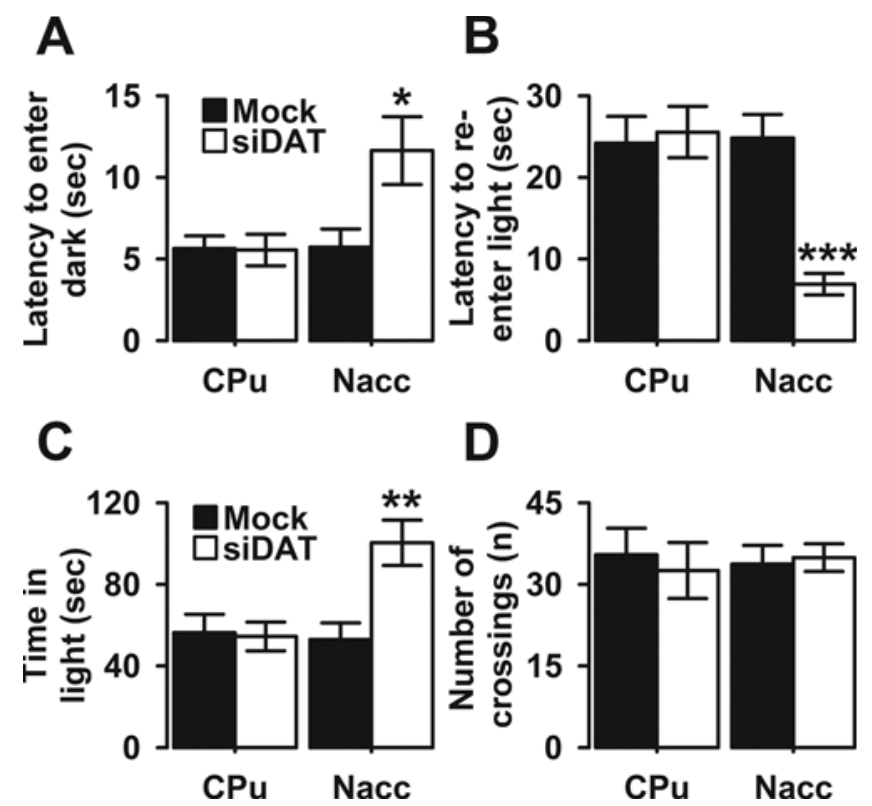

D

Fig. 2. Anxiety-like behavior in Mock- and siDAT-injected mice in the LDB test. The data are expressed as mean \pm SEM for the A) latency to enter the dark box, B) latency to reenter the light box, C) total time spent in the light box, and D) number of crossings between the light and dark boxes. ${ }^{*} p<0.05,{ }^{* *} p<$ 0.005 and $* * * p<0.001$ indicate significant differences between Mock- and siDAT-injected mice in the Nacc. For each group $n=11$.

$\left.\mathrm{F}_{(3,40)}=0.940, p=0.430\right)($ Fig. $2 \mathrm{D})$.

\subsection{DAT knockdown in the Nacc altered depression-like behavior}

\subsubsection{Sucrose preference test (SPT)}

During the SPT, the mice could drink either tap water or a $2 \%$ sucrose solution and the results are shown in Fig. 3. The latency to drink after the bottles were presented was analyzed using a two-way ANOVA and the Levene's test for equality of variances was found to be statistically non-significant $\left(\mathrm{F}_{(3,40)}=1.998, p=0.130\right)$, but there was a significant main effect of viral injection $\left(\mathrm{F}_{(1,40)}=5.151, p=0.029\right)$ and brain region $\left(\mathrm{F}_{(1,40)}=6.138, p=0.018\right)$. Also, the viral-injection $\times$ brain region interaction term was significant $\left(\mathrm{F}_{(1,40)}=6.575, p=\right.$ 0.014 ) (Fig. 3A). Bonferroni post hoc testing indicated that Nacc siDAT- 
A

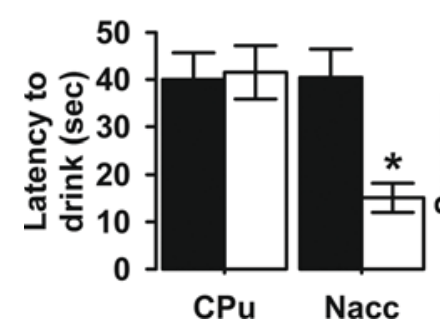

B

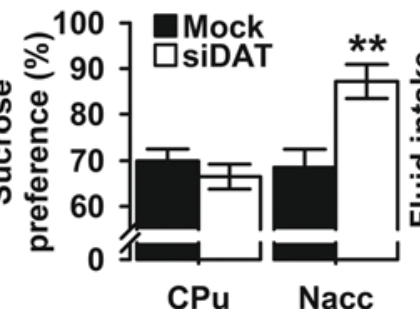

C

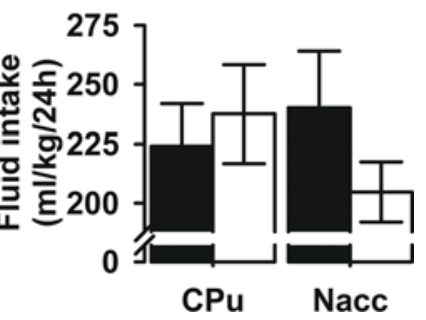

Fig. 3. Depression-like behavior in Mock- and siDAT-injected mice in the SPT. The data are expressed as mean \pm SEM for the A) latency to initiate sucrose drinking, B) sucrose preference, and $C$ ) total fluid intake in milliliters per kilogram of body weight. ${ }^{*} p<0.01$ and $* * p<0.005$ indicate significant differences between Mock- and siDAT-injected mice in the Nacc. For each group $\mathrm{n}=11$. injected mice, but not $\mathrm{CPu}$, showed a significantly shorter latency time than Mock controls ( $p=0.009$ and $p=1.000$ respectively). In addition, sucrose preference was significantly affected by viral-injection $\left(\mathrm{F}_{(1,40)}=5.305, p=0.027\right)$, and brain region $\left(\mathrm{F}_{(1,40)}=8.433, p=\right.$ 0.006) with a significant interaction between the two factors $\left(\mathrm{F}_{(1,40)}=11.050, p=0.002\right)$ (Levene's test: $\mathrm{F}_{(3,40)}=1.082, p=$ 0.368) (Fig. 3B). Pairwise comparisons revealed that, in the Nacc group, siDAT-injected mice showed a significantly higher preference for $2 \%$ sucrose ( $p=0.002$, Bonferroni post hoc) which confirmed an increased hedonic response as a consequence of Nacc DAT knock-down. Importantly, the mean daily fluid consumption (sucrose + water) per body weight was not significantly different between the four-experimental groups; main effect of viral injection $\left(\mathrm{F}_{(1,40)}=0.324, p=\right.$ $0.572)$, main effect of brain region $\left(\mathrm{F}_{(1,40)}=0.190, p=0.665\right)$, interaction $\left(\mathrm{F}_{(1,40)}=1.600, p=0.213\right)$ (Levene's test: $\mathrm{F}_{(3,40)}=2.125$,

\subsubsection{Novelty-suppressed feeding (NSF)}

After $24 \mathrm{~h}$ of food deprivation, the changes in body weight were not significantly different in the four-experimental groups (main effect of viral-injection: $\mathrm{F}_{(1,40)}=0.375, p=0.544$ ) (Data not shown). However, in the test box the latency to initiate eating was affected by viral-injection $\left(\mathrm{F}_{(1,40)}=6.616, p=0.014\right)$, and brain region $\left(\mathrm{F}_{(1,40)}=8.234\right.$, $p=0.007)$. Consequently, the interaction between the two independent variables was found significant $\left(\mathrm{F}_{(1,40)}=13.125, p=\right.$ 0.001), but the Levene's test for equality of variances was found to be statistically non-significant $\left(\mathrm{F}_{(3,40)}=1.550, p=0.216\right.$ ) (Fig. 4A). Post hoc analyses revealed that, when injected in the Nacc, siDAT mice showed a significantly shorter latency to bite into pellets as compared to Mock controls $(p<0.0001)$ (Fig. 4A). In addition, and during the 15 -min test period, siDAT-injected mice spent significantly more time $p=0.112$ ) (Fig. 3C).
A

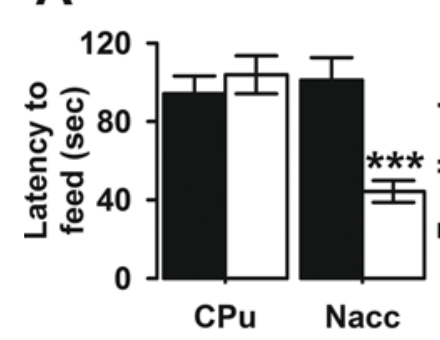

B
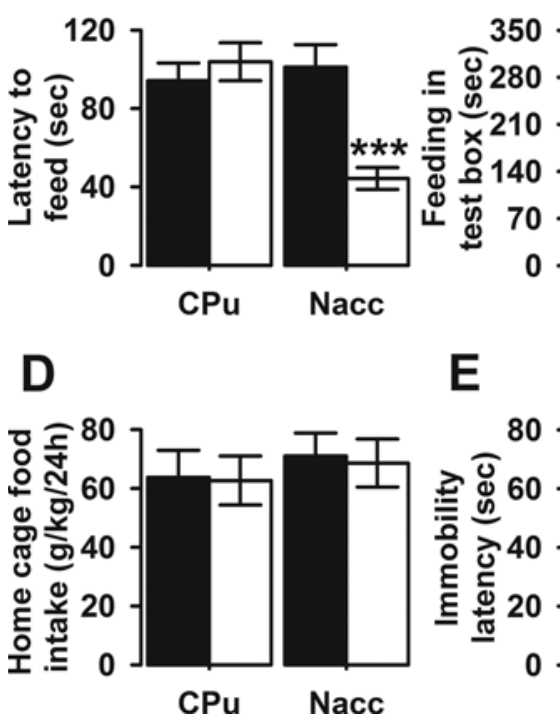

E

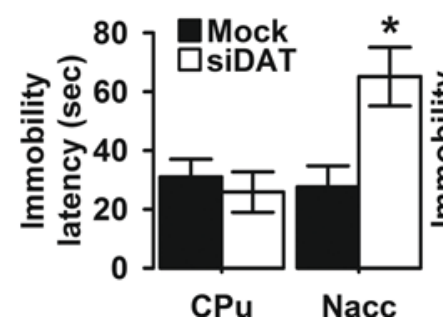

eating; main effect of viral injection $\left(\mathrm{F}_{(1,40)}=6.682, p=0.013\right)$, main effect of brain region $\left(\mathrm{F}_{(1,40)}=7.116, p=0.011\right)$, interaction $\left(\mathrm{F}_{(1,40)}=8.078, p=0.007\right)$ (Levene's test: $\mathrm{F}_{(3,40)}=2.084, p=0.118$ ) (Fig. 4B). Again, the siDAT effects were driven by the Nacc group, which was significantly different between the viral-injection conditions ( $p=0.003$, Bonferroni post hoc), whereas the CPu group did not differ between Mock and siDAT-injected rats $(p=1.000$, Bonferroni post hoc). Similarly, DAT knockdown yielded a greater food intake during the test; main effect of viral injection $\left(\mathrm{F}_{(1,40)}=8.288, p=0.006\right)$, main effect of brain region $\left(\mathrm{F}_{(1,40)}=4.570, p=0.039\right)$, interaction $\left(\mathrm{F}_{(1,40)}=8.288, p=0.006\right)$ (Levene's test: $\left.\mathrm{F}_{(3,40)}=0.254, p=0.858\right)$ (Fig. 4C). It should be mentioned that the siDAT effects on food intake during the NSF test were mainly driven by the Nacc group, which differentially and significantly affected the Mock- and siDAT-injected groups ( $p=0.001$, Bonferroni post hoc). However, after returning to their home cage, the daily total food consumption was not significantly different between the four experimental groups; main effect of viral injection $\left(\mathrm{F}_{(1,40)}=0.041, p=0.840\right)$, main effect of brain region $\left(\mathrm{F}_{(1,40)}=0.623, p=0.435\right)$, interaction $\left(\mathrm{F}_{(1,40)}=0.006, p=0.940\right)$ (Levene's test: $\mathrm{F}_{(3,40)}=0.392, p=0.760$ ) (Fig. 4D).

\subsubsection{Forced-swim test (FST)} tency to immobility, a significant effect was seen of both viral-injection $\left(\mathrm{F}_{(1,40)}=4.484, p=0.040\right)$, brain region $\left(\mathrm{F}_{(1,40)}=5.551, p=0.023\right)$ and of the interaction between the two factors $\left(\mathrm{F}_{(1,40)}=7.825, p=\right.$ 0.008) (Levene's test: $F_{(3,40)}=0.991, p=0.407$ ) (Fig. 4E). Post hoc evaluations indicated that Nacc siDAT-injected mice showed prolonged latency to immobility compared to Mock controls $(p=0.007)$ which is also a sign of anti-depression-like behavior in the rodent FST. Finally, and as showed in Fig. 4F, the two-way ANOVA showed significant
In this last test, the two-way ANOVA analysis revealed that for la-
C

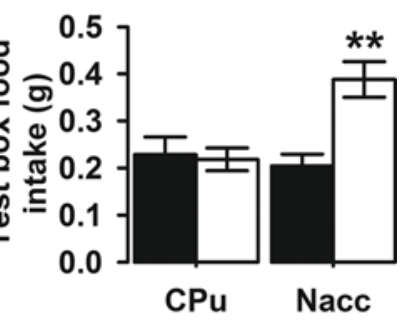

$\mathbf{F}$

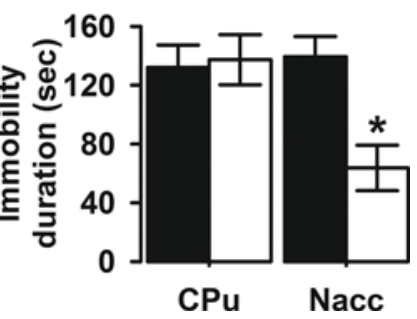

Fig. 4. Depression-like behavior in Mock- and siDAT-injected mice in the NSFT and FST. The data are expressed as mean \pm SEM for the A) latency to feed, B) feeding time in the test box in (sec/15 min), C) food consumed in the test box ( $\mathrm{g} / 15 \mathrm{~min})$, and $\mathrm{D}$ ) food consumed in the home cage expressed as grams per kilogram of body weight per $24 \mathrm{~h}(\mathrm{~g} / \mathrm{kg} / 24 \mathrm{~h})$ in the NSFT, E) latency to initiate immobility, and F) total immobility time in the FST. ${ }^{*} p<0.01$, $* * p<0.005$, and $* * * p<0.001$ indicate significant differences between Mock- and siDAT-injected mice in the Nacc. For each group $\mathrm{n}=11$. 

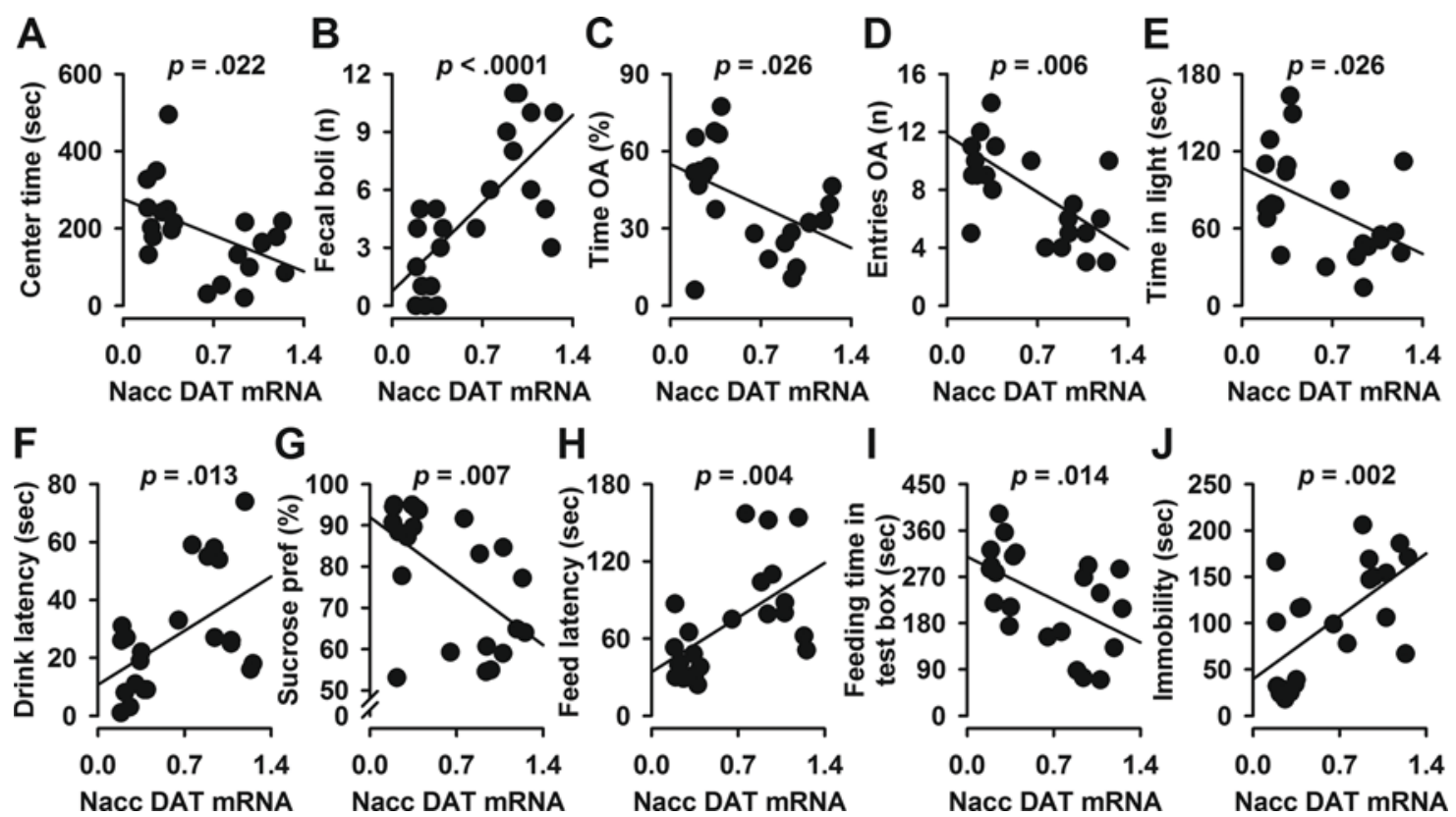

Fig. 5. Pearson's correlations. The data represent simple scatter regression between DAT mRNA levels in the Nacc with A) time spent in the center of the arena, B) number of fecal boli of the OF test, C) percentage of time into the OA, D) number of entries into the OA of the EPM test, E) total time spent in the light box in the LDB test, F) latency time to initiate sucrose drinking, G) sucrose preference of the SPT, H) latency time to initiate eating, I) time spent feeding in the test box during the 15min test period of the NSFT, and J) total time spent immobile in the FST.

effects of both viral-injection $\left(\mathrm{F}_{(1,40)}=5.186, p=0.028\right)$ and brain region $\left(\mathrm{F}_{(1,40)}=4.587, p=0.038\right)$, and of their interaction on immobility $\left.\left(\mathrm{F}_{(} 1,40\right)=6.890, p=0.012\right)$ (Levene's test: $\mathrm{F}_{(3,40)}=0.218$, $p=0.883$ ). Although there was a main effect of brain region across both groups, post hoc tests revealed that this effect was driven by the Nacc group. Indeed, immobility duration was significantly lower in Nacc mice injected with siDAT compared to Mock controls $(p=0.008$, Bonferroni post hoc test). In contrast, no significant differences were found in the $\mathrm{CPu}$ group between Mock-and siDAT-injected mice ( $p=$ 1.000 , Bonferroni post hoc test). These results indicate that the knockdown of DAT in the Nacc, but not in the $\mathrm{CPu}$, attenuated depression-like behavior.

3.4. DAT mRNA in the Nacc correlated with anxiety- and depression-like behaviors

Pearson's correlation was used to establish the relationship between DAT mRNA levels in the Nacc, and measures of anxiety- and depressionlike behaviors and findings are displayed in Fig. 5 and Suppl. Fig. 2. In the OF test, the results have shown that DAT mRNA correlated negatively with the time spent in the center of the arena $(r=-0.486, p=$ 0.022; Fig. 5A), and positively with number of fecal boli recovered from the OF test $(r=0.714, p<0.0001$; Fig. 5B). However, there was no correlation between DAT mRNA levels and the number of line crossings $(r=0.112, p=0.619$; Suppl. Fig. 2A). In the EPM test, the Pearson's correlation coefficients revealed a negative correlation between DAT mRNA levels with the proportion of time spent in the OA (Pearson's test: $r=-0.474, p=0.026$; Fig. $5 \mathrm{C}$ ). Also, we found a negative correlation between DAT mRNA with the number $(r=-0.565, p=$ 0.006; Fig. 5D), and the percentage of entries into the OA $(r=-0.596$, $p=0.003$; Suppl. Fig. 2B), but not with the number of CA entries $(r=0.272, p=0.221$; Suppl. Fig. 2C). In addition, the Pearson correlation coefficient was used to determine any relationship between DAT mRNA expression and the parameters of the LDB test and the results indicated that DAT mRNA correlated negatively with the time spent in the light side of the box ( $r=-0.474, p=0.026$; Fig. 5E) and with the latency to enter the dark side of the box $(r=-0.563, p=$ 0.006; Suppl. Fig. 2D). However, there was a strong positive correlation between DAT mRNA with the latency to re-enter the light side of the box ( $r=0.579, p=0.005$; Suppl. Fig. $2 \mathrm{E}$ ), but not with the number of crossings between light and dark sides of the box $(r=-0.059, p=$ 0.795; Suppl. Fig. 2F). For depression-like behavior measures, DAT mRNAs correlated positively with the latency to drink sucrose $(r=0.523, p=0.013$; Fig. $5 \mathrm{~F})$, and negatively with the sucrose preference ( $r=-0.556, p=0.007$; Fig. $5 \mathrm{G}$ ), but not with mean daily fluid consumption (sucrose + water) per body weight $(r=0.206, p=$ 0.357; Suppl. Fig. 2G). Similarly, the Pearson's correlation coefficients indicate matching between DAT mRNA expression with the latency to bite into pellets $(r=0.582, p=0.004$; Fig. $5 \mathrm{H})$. However, DAT mRNA correlated negatively with the time spent feeding $(r=-0.515, p=$ 0.014; Fig. 5I), and food intake ( $r=-0.549, p=0.008$; Suppl. Fig. $2 \mathrm{H}$ ) in the test box during the test period, but not with the home cage daily total food consumption $(r=-0.034, p=0.882$; Suppl. Fig. 2I). Finally, DAT mRNA in the Nacc correlated negatively with the latency to the first immobility period $(r=-0.424, p=0.049$; Suppl. Fig. 2J), and positively with the immobility time $(r=0.628, p=$ 0.002 ; Fig. 5J). Taken together, these findings suggest that mice with low DAT mRNA expression levels in the Nacc are most likely to correlate with reduced anxiety- and depression-like phenotypes.

3.5. DAT mRNA in the CPu did not correlate with anxiety- and depressionlike behaviors

We also used Pearson's correlation to establish the relationship between DAT mRNA levels in the $\mathrm{CPu}$, and measures of anxiety- and depression-like behaviors. The findings are displayed in Fig. 6 and Suppl. Fig. 3. In the OF test, the results have shown that DAT mRNA had no correlation with the time spent in the center of the arena $(r=$ $-0.119, p=0.596$; Fig. $6 \mathrm{~A})$, the number of fecal boli $(r=-0.072$, $p=0.750$; Fig. 6B), or the number of line crossings ( $r=-0.051, p=$ 0.821; Suppl. Fig. 3A). Also, in the EPM test the Pearson's correlation coefficients revealed no correlation between DAT mRNA with the time spent in the OA $(r=-0.061, p=0.788$; Fig. $6 \mathrm{C})$, the number $(r=$ $-0.037, p=0.870$; Fig. $6 \mathrm{D}$ ), and the percentage of entries in to the $\mathrm{OA}$ $(r=0.001, p=0.998$; Suppl. Fig. 3B), or the number of CA entries ( $r$ $=-0.019, p=0.935$; Suppl. Fig. 2C). In the LDB test, DAT mRNA did 
A

B
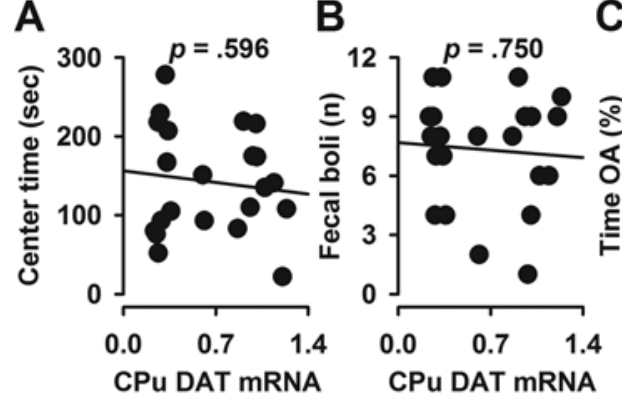

C

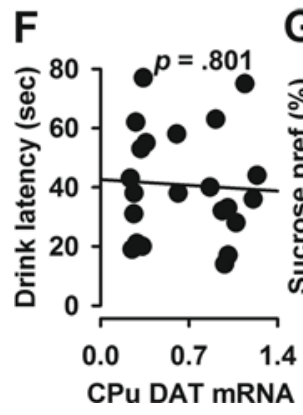

G

CPu DAT mRNA
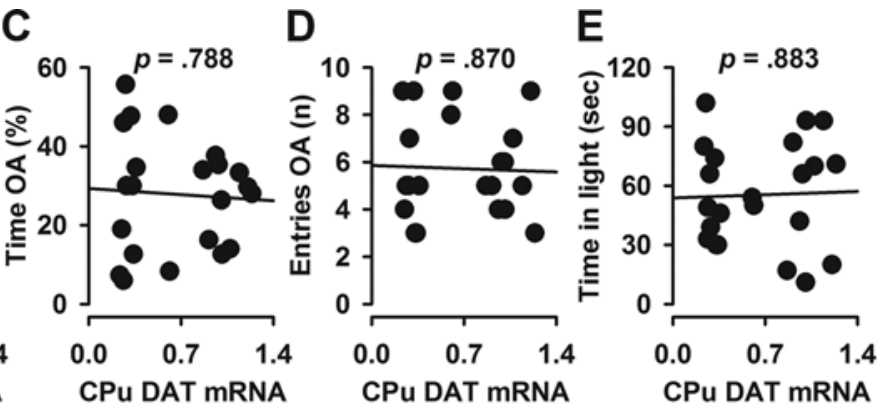

Fig. 6. Pearson's correlations. The data represent simple scatter regression between DAT mRNA levels in the CPu with A) time spent in the center of the arena, B) number of fecal boli of the OF test, C) percentage of time into the OA, D) number of entries into the OA of the EPM test, E) total time spent in the light box in the LDB test, F) latency time to initiate sucrose drinking, G) sucrose preference of the SPT, H) latency time to initiate eating, I) time spent feeding in the test box during the 15min test period of the NSFT, and J) total time spent immobile in the FST.

not correlate with the time spent in the light side of the box ( $r=0.033$, $p=0.883$; Fig. $6 \mathrm{E}$ ), the latency to enter the dark side of the box ( $r=0.010, p=0.963$; Suppl. Fig. 3D), the latency to re-enter the light side of the box ( $r=-0.160, p=0.476$; Suppl. Fig. 3E), or the number of transitions ( $r=0.048, p=0.831$; Suppl. Fig. 3F). For depressionlike behavior measures, DAT mRNAs did not correlate with the drinking latency $(r=-0.057, p=0.801$; Fig. $6 \mathrm{~F})$, the sucrose preference $(r=0.151, p=0.502$; Fig. $6 \mathrm{G})$, or with the total fluid intake $(r=$ $-0.313, p=0.156$; Suppl. Fig. 3G). For the NSF test, there was no correlation between DAT mRNA with feeding latency $(r=-0.165$, $p=0.462$; Fig. $6 \mathrm{H})$, feeding time ( $r=0.032, p=0.888$; Fig. 6I), food intake $(r=-0.121, p=0.592$; Suppl. Fig. 3H) in the test box during the test period, or with food intake in the home cage $(r=0.015, p=$ 0.948; Suppl. Fig. 3I). Finally, DAT mRNA in the CPu did not correlate with the latency to the first immobility period $(r=0.059, p=0.795$; Suppl. Fig. 3J), or with the immobility time ( $r=-0.251, p=0.260$; Fig. $6 \mathrm{~J}$ ). Taken together, these findings suggest that low DAT mRNA expression levels in the CPu had no effect on measures of anxiety- and depression-like behaviors.

\section{Discussion}

In the present study we examined the effects of DAT manipulation on anxiety- and depression-like behaviors in adult mice. The major findings are that lentiviral-mediated knock down of DAT in the Nacc, but not in the $\mathrm{CPu}$, triggered an anxiolytic-like effect, demonstrated, consistently, by significant behavioral alterations in the OF test (central area entry, and number of fecal boli), the EPM test (time spent and entries into the open arms), and LDB test (latency to enter the dark side and time spent in the light side of the box). In addition, DAT knock down also altered depression-like behavior in the SPT (latency and sucrose preference), the NSF (latency to initiate eating and food intake in the test box), and the FST (latency to initiate immobility and immobility time). We also showed that stereotaxic injection of DAT siRNA-expressing lentiviral vectors stably reduced DAT mRNA expression in both regions. However, measures of anxiety and depression parameters only correlated with DAT mRNA alterations in the Nacc. DAT has been found to be highly expressed in brain regions associated with mood disorders. For example, Richtand and colleagues reported more than 20 years ago that DAT mRNA was differentially expressed in the brain and was detected solely in cell bodies of dopaminergic neurons with highest localization patterns in the SNc/VTA [66]. Also, using immunohistochemistry, DAT was found in areas with well-known dopaminergic circuitry such as the mesostriatal, mesolimbic, and mesocortical pathways, DAT-immunoreactivity was enhanced in the SNc and VTA with dense and heterogeneous staining in the striatum and Nacc [67]. Given its anatomical distribution, many studies have implicated DAT in the pathophysiology of psychiatric disorders [23-25].

To further investigate the physiological implication of DAT in mood disorders, we explored the effect of DAT manipulation on anxiety- and depression-like behaviors in adult mice using DAT shRNA-expressing lentiviral vectors. These vectors have been successfully used in our previous studies $[26,27,37]$. Using OF, EPM and LDB tests we found that anxiety-like behavior was reduced following DAT knock-down in the Nacc. More importantly, these effects were region specific as DAT manipulation in the $\mathrm{CPu}$ had no effect. Our findings are perfectly in line with previously published studies using DAT deficient mice in which anxiety-like behavior seemed to be reduced, compared to WT controls, in the EPM and LDB assays [68]. Also, and compared to WT, DAT KO mice spent more time in the OA, suggesting that they were less anxious in the EPM test, with no indication of hyperactivity, as both genotypes showed the same number of total entries [69]. In addition, transgenic mice lacking the limbic system-associated membrane protein (Lsamp) gene displayed reduced anxiety that was associated with lower level of DAT mRNA in the mesencephalon as measured by qRT-PCR [70]. However, other results showed that DAT ablation-induced alterations, affected locomotor activity in a novel as well as in a familiar environment because, when repetitively exposed to the same environment for a long duration (up to $10 \mathrm{~h}$ ), DAT KO showed no locomotor adaptation [71]. In the mice striatum, disruption of DAT gene leads to a $50 \%$ reduction or complete ablation of DAT expression of heterozygous (HET) and KO [72]. Using quantitative RT-PCR we showed that the reduction in DAT expression is approximately $70 \%$. In terms of comparisons to genetically modified mice this places this degree of reduction, using siRNA-expressing lentiviral vectors, somewhere between HET and KO mice (e.g. between a $50 \%$ and $100 \%$ reduction in DAT expression), and 
our findings are somehow in line of those of Pogorelov and colleagues. In fact, and compared to other genotypes, HET mice are less anxious they are actively involved in novelty-seeking behaviors that include increased time spent in the center of the OF, enhanced investigation of objects, and increased free exploration of a novel environment [73]. In contrast, KO mice exhibited neophobia when originally exposed to novel conditions. Over time the anxiety-like response acclimatizes and behaviors become activated and stereotyped, these behaviors are distinct from exploration or novelty seeking [73]. Eventhough increased activity in the center zone across days is suggestive of cocaine-induced behavioral sensitization in naive animals [74], it is legitimate to speculate that they are associated to exploration. One possible explanation is that the formation of a regular exploratory behavior of the novel environment was affected by the significant hyperactivity of DAT KO, which in turn prevents the locomotor adaptation during subsequent introduction to the environment. In the contrary, the anxiolytic-like phenotype observed in the current study following DAT knockdown in the Nacc was not associated to locomotor impairment, suggesting that, compared to genetically engineered transgenic mice, viral vectors' technology was a relatively reliable method for in vivo assessment of DAT in the brain. Regardless, the manifestation of anxiety disorders required a functional DAT because in a previous report, Yorgason and colleagues found a significant negative correlation between EPM openarm time and both dopamine release and uptake [75] regulated by increased transporter activity, supporting the idea that elevated accumbal dopaminergic transmission may be correlated with increased anxiety-like behavior.

The relationship between anxiety and DAT/dopamine activity is rather inconsistent and may vary by brain region. For example, although systemic injection of apomorphine in rats (dopaminergic agonist) produced an anxiolytic-like response [76], intra-basolateral amygdala (BLA) infusion of either SKF38393 or quinpirole, D1 and D2 agonists respectively, increased anxiety-like behaviors [77]. More surprisingly, a potential differential and opposing role of dopamine in the central versus the basolateral amygdala was reported [78]. Taken together, although, the exact mechanism is not clear, our finding of significant correlations between OF and EPM measures and DAT mRNA expression supports the conception that lower accumbal DAT levels may be related with decreased anxiety-like behavior.

We also investigated whether DAT manipulation is involved in depression-like behavior using SPT, NSFT and FST. Our findings suggested that depression-like behavior was attenuated in siDAT-expressing mice. In fact, sucrose preference, latency to feed and immobility time were significantly reduced following DAT mRNA knockdown using shRNAexpressing viral vectors, in the Nacc, compared with control mice (Mock vector), suggesting that DAT activity in the Nacc, but not in the $\mathrm{CPu}$, plays a crucial role in depression-like behavior in mice. Our findings agree with those of Dutta and colleagues who showed that the monoamine transporter inhibitor D-161, showed significant activity in reducing immobility in the FST and TST with no effect on motor activation [79]. Also, DAT blocker bupropion ( 2 and $4 \mathrm{mg} / \mathrm{kg}$ ), tested using the FST, decreased the immobility time of the inbred mouse strain C57BL/6 J Rj [80], and produced clinically effective anti-depressant actions, with in vivo brain microdialysis studies demonstrating that, accumbal extracellular dopamine increased following chronic administration of bupropion [81]. More recently, it was found that depressed patients had greater DAT expression on both sides of the striatum and that bupropion's treatment reduced significantly DAT binding in the striatum [82]. Also, the triple reuptake inhibitors JZAD-IV-22, TP1, and $\mathrm{D}-473$ that block the dopamine, norepinephrine, and serotonin transporters exhibited antidepressant-like efficacy in the FST and/or TST without locomotor stimulant or sensitization properties [83-85]. However, deep brain stimulation of the medial forebrain bundle in male Wistar rats showed a significant increase in swimming duration, that was associated to a significant increase in DAT protein expression in the hippocampus [86].
To examine the role of DAT in models of depression, KO mice were studied in the FST and TST and results indicated that DAT transgenics exhibited less immobility. In the same study, DAT KO showed a significant higher consumption of sucrose solution, in the SPT, compared to their WT controls, indicating decreased anhedonia in DAT transgenics [87], suggesting an overall anti-depressant-like phenotype. One can speculate that alterations in behavior in the FST between DAT transgenics and their WT littermates were due to increase hyperactivity (in DAT KO) as concluded in a previous study [71]. However, Perona and colleagues clearly showed that swimming, and immobility were almost abolished in DAT KO, replaced with tenacious and continuous climbing (e.g. escape attempts) [87], indicating an anti-depressant-like behavior.

For DAT constitutive KO mice, it is virtually impossible to assign behavioral alterations to a specific brain structure or pathway, or even to the nervous system as the mutation is present in all cells of the brain as well as many peripheral organs. Also, because the mutation is present from the earliest stages of development, it is generally uncertain whether the observed phenotypic changes are the result of DAT loss or whether it is due to functional compensatory properties that the animal has adapted throughout development. To overcome these limitations, we strongly believe that, compared to DAT constitutive KO mice, the lentiviral-mediated gene transfer approach, used in the current study, is a relatively rapid and reliable method for in vivo assessment of DAT in the brain. In fact, the stereotaxic injection is believed to be tissue-specific providing a spatial control. In addition, DAT knockdown occurred in a temporally-selective manner in the adult mouse and does not include any possibility of compensatory adaptations during development. In support of our findings, optogenetic stimulation of VTA dopaminergic neurons, using adeno-associated virus, relieves chronic stressinduced depressive behavior in FST [88] suggesting that hypodopaminergia may be implicated in depressive-like behaviors.

Although, the detailed neuronal mechanisms underlying the antidepressant effects of DAT knockdown are not clear, the outcome from the current study indicates that enhancing dopaminergic signaling may be sufficient to observe antidepressant-like effects in three behavioral models. In fact, reduced dopamine activity in the mesocortical circuit is suggested to play a critical role in expressing anhedonia, a core symptom of depression in humans [89]. Therefore, we speculate that DAT reductions in the Nacc would certainly be associated with increased dopamine levels and that the increase in sucrose preference and decrease immobility in the current study may reflect this mechanism. In fact, drugs that increase dopamine release/function have an antidepressant-like profile in patients and animal models of depression $[90,91]$. One could argue that the molecular measurements were performed following the behavioral tests. This raises the possibility that the changes of DAT expression levels observed in the Nacc may be the result of the lentiviral injection, the alterations in behavior, or both. Further studies are needed to a better understanding of this issue.

Despite the fact that studies using imaging techniques yielded conflicting results, there is substantial evidence for a role of DAT in depression in humans. For example, using SPECT with a high-affinity DAT radioligand, studies indicated that, in patients with MDD, DAT density was significantly higher comparted to controls [92,93]. However, when the density of DAT was assessed in other studies, the data indicated decreases in striatal DAT binding in depressed patients [24,94]. Likewise, in Parkinsonian patients, measures for anxiety and depression were associated with diminished left anterior putamen DAT binding [95], and striatal DAT binding was significantly lower in depressed versus non-depressed cervical dystonia patients [96]. The significant flaw in the results reported above is the absence of repeated cross-sectional studies that examine variations during phases of illness. Preferably future studies should focus on clarifying phase-related DAT alterations by studying patients in depressive episodes to determine the direction of causality. 


\section{Conclusion}

In Summary, DAT knockdown in the Nacc, but not in the $\mathrm{CPu}$, improve anxiety- and depression-like symptoms in adult mice and the data illustrate the complex way DAT contributes to emotional behavior. Although dopamine/DAT interactions with affective disorders are still being clarified, our findings support the possibility that developing new selective DAT inhibitors would be of great therapeutic value against anxiety and depression disorders.

\section{Authors' contribution}

$A B$ designed the study and wrote the protocol. $A B$ and JLD managed the literature searches and analyses. $A B$ undertook the statistical analysis, and $A B$ and JLD wrote the first draft of the manuscript. All authors contributed to and have approved the final manuscript.

\section{Role of the funding source}

$\mathrm{AB}$ was supported by grants from the United Arab Emirates University (No. NP/13/05) and the National Research foundation (No. 31M082). JLD received grants from the Swiss National Science Foundation3100-059350 and 3100AO-100686. The funders had no further role in study design, analysis, writing of the report, or in the decision to submit the paper for publication.

\section{Disclosure/conflict of interest}

The authors have no financial interests that might be perceived to influence the results, or the discussion reported in this article.

\section{Acknowledgments}

The authors would like to acknowledge Mrs. Christine DeforelPoncet and Dr. Frederic Boyer for their technical assistance with the lentiviral vectors' preparation. The authors are also grateful to Mr. Mohamed Shafiullah and Dr. Mahmoud Hag Ali from the Central Animal Facility for their advice on animal care and welfare.

\section{Appendix A. Supplementary data}

Supplementary data associated with this article can be found, in the online version, at https://doi.org/10.1016/j.bbr.2018.10.028.

\section{References}

[1] WHO, Depression and Other Common Mental Disorders: Global Health Estimates, (2017).

[2] T. Lancet, GBD 2015: from big data to meaningful change, Lancet 388 (10053) (2016) 1447.

[3] K. Kitahama, I. Nagatsu, M. Geffard, T. Maeda, Distribution of dopamine-immunoreactive fibers in the rat brainstem, J. Chem. Neuroanat. 18 (1-2) (2000) 1-9.

[4] R. Adolfsson, C.G. Gottfries, B.E. Roos, B. Winblad, Post-mortem distribution of dopamine and homovanillic acid in human brain, variations related to age, and a review of the literature, J. Neural Transm. 45 (2) (1979) 81-105.

[5] S. Hama, T. Murakami, H. Yamashita, K. Onoda, S. Yamawaki, K. Kurisu, Neuroanatomic pathways associated with monoaminergic dysregulation after stroke, Int. J. Geriatr. Psychiatry (2016)

[6] K.A. Raczka, M.L. Mechias, N. Gartmann, A. Reif, J. Deckert, M. Pessiglione, R. Kalisch, Empirical support for an involvement of the mesostriatal dopamine system in human fear extinction, Transl. Psychiatry 1 (2011) e12.

[7] J. Tiihonen, J. Kuikka, K. Bergstrom, U. Lepola, H. Koponen, E. Leinonen, Dopamine reuptake site densities in patients with social phobia, Am. J. Psychiatry 154 (2) (1997) 239-242.

[8] J. Sareen, D.W. Campbell, W.D. Leslie, K.L. Malisza, M.B. Stein, M.P. Paulus, L.B. Kravetsky, K.D. Kjernisted, J.R. Walker, J.P. Reiss, Striatal function in generalized social phobia: a functional magnetic resonance imaging study, Biol. Psychiatry 61 (3) (2007) 396-404.

[9] W.A. Cass, N.R. Zahniser, K.A. Flach, G.A. Gerhardt, Clearance of exogenous dopamine in rat dorsal striatum and nucleus accumbens: role of metabolism and effects of locally applied uptake inhibitors, J. Neurochem. 61 (6) (1993) 2269-2278.
[10] J.A. Moron, A. Brockington, R.A. Wise, B.A. Rocha, B.T. Hope, Dopamine uptake through the norepinephrine transporter in brain regions with low levels of the dopamine transporter: evidence from knock-out mouse lines, J. Neurosci. 22 (2) (2002) 389-395.

[11] B. Giros, S. el Mestikawy, L. Bertrand, M.G. Caron, Cloning and functional characterization of a cocaine-sensitive dopamine transporter, FEBS Lett. 295 (1-3) (1991) 149-154.

[12] J.U. Fog, H. Khoshbouei, M. Holy, W.A. Owens, C.B. Vaegter, N. Sen, Y. Nikandrova, E. Bowton, D.G. McMahon, R.J. Colbran, L.C. Daws, H.H. Sitte, J.A. Javitch, A. Galli, U. Gether, Calmodulin kinase II interacts with the dopamine transporter $\mathrm{C}$ terminus to regulate amphetamine-induced reverse transport, Neuron 51 (4) (2006) 417-429.

[13] M.C. Shih, M.Q. Hoexter, L.A. Andrade, R.A. Bressan, Parkinson's disease and dopamine transporter neuroimaging: a critical review, Sao Paulo Med. J. 124 (3) (2006) 168-175.

[14] N. Sinha, M. Firbank, J.T. O’Brien, Biomarkers in dementia with Lewy bodies: a review, Int. J. Geriatr. Psychiatry 27 (5) (2012) 443-453.

[15] P. Seeman, H.B. Niznik, Dopamine receptors and transporters in Parkinson's disease and schizophrenia, FASEB J. 4 (10) (1990) 2737-2744.

[16] S. Kasper, J. Tauscher, M. Willeit, M. Stamenkovic, A. Neumeister, B. Kufferle, C. Barnas, J. Stastny, N. Praschak-Rieder, L. Pezawas, M. de Zwaan, S. Quiner, W. Pirker, S. Asenbaum, I. Podreka, T. Brucke, Receptor and transporter imaging studies in schizophrenia, depression, bulimia and Tourette's disorder-implications for psychopharmacology, World J. Biol. Psychiatry 3 (3) (2002) 133-146.

[17] W.L. Nyhan, Dopamine function in Lesch-Nyhan disease, Environ. Health Perspect. 108 (Suppl 3) (2000) 409-411.

[18] D. Leo, R.R. Gainetdinov, Transgenic mouse models for ADHD, Cell Tissue Res. 354 (1) (2013) 259-271.

[19] V. Narayanaswami, A.C. Thompson, L.A. Cassis, M.T. Bardo, L.P. Dwoskin, Dietinduced obesity: dopamine transporter function, impulsivity and motivation, Int. J. Obes. (Lond.) 37 (8) (2013) 1095-1103.

[20] G. Camardese, D. Di Giuda, M. Di Nicola, F. Cocciolillo, A. Giordano, L. Janiri, R. Guglielmo, Imaging studies on dopamine transporter and depression: a review of literature and suggestions for future research, J. Psychiatr. Res. 51 (2014) 7-18.

[21] C.N. Haile, T.R. Kosten, T.A. Kosten, Pharmacogenetic treatments for drug addiction: cocaine, amphetamine and methamphetamine, Am. J. Drug Alcohol Abuse 35 (3) (2009) 161-177.

[22] S.P. Runyon, F.I. Carroll, Dopamine transporter ligands: recent developments and therapeutic potential, Curr. Top. Med. Chem. 6 (17) (2006) 1825-1843.

[23] J.A. den Boer, Social anxiety disorder/social phobia: epidemiology, diagnosis, neurobiology, and treatment, Compr. Psychiatry 41 (6) (2000) 405-415.

[24] J.H. Meyer, S. Kruger, A.A. Wilson, B.K. Christensen, V.S. Goulding, A. Schaffer, C. Minifie, S. Houle, D. Hussey, S.H. Kennedy, Lower dopamine transporter binding potential in striatum during depression, Neuroreport 12 (18) (2001) 4121-4125.

[25] A. Anand, G. Barkay, M. Dzemidzic, D. Albrecht, H. Karne, Q.H. Zheng, G.D. Hutchins, M.D. Normandin, K.K. Yoder, Striatal dopamine transporter availability in unmedicated bipolar disorder, Bipolar Disord. 13 (4) (2011) 406-413.

[26] W. Adriani, F. Boyer, L. Gioiosa, S. Macri, J.L. Dreyer, G. Laviola, Increased impulsive behavior and risk proneness following lentivirus-mediated dopamine transporter over-expression in rats' nucleus accumbens, Neuroscience 159 (1) (2009) 47-58.

[27] W. Adriani, F. Boyer, D. Leo, R. Canese, F. Podo, C. Perrone-Capano, J.L. Dreyer, G. Laviola, Social withdrawal and gambling-like profile after lentiviral manipulation of DAT expression in the rat accumbens, Int. J. Neuropsychopharmacol. 13 (10) (2010) 1329-1342.

[28] L. Booij, C.A. Swenne, J.F. Brosschot, P.M. Haffmans, J.F. Thayer, A.J. Van der Does, Tryptophan depletion affects heart rate variability and impulsivity in remitted depressed patients with a history of suicidal ideation, Biol. Psychiatry 60 (5) (2006) 507-514.

[29] J.L. Hudson, M. Gradisar, A. Gamble, C.A. Schniering, I. Rebelo, The sleep patterns and problems of clinically anxious children, Behav. Res. Ther. 47 (4) (2009) 339-344.

[30] K. Laas, D. Eensoo, M. Paaver, K.P. Lesch, A. Reif, J. Harro, Further evidence for the association of the NPSR1 gene A/T polymorphism (Asn107Ile) with impulsivity and hyperactivity, J. Psychopharmacol. 29 (8) (2015) 878-883.

[31] G.K. O'Malley, L. McHugh, N. Mac Giollabhui, J. Bramham, Characterizing adult attention-deficit/hyperactivity-disorder and comorbid borderline personality disorder: ADHD symptoms, psychopathology, cognitive functioning and psychosocial factors, Eur. Psychiatry 31 (2016) 29-36.

[32] C. Lahmann, R.H. Clark, M. Iberl, F.M. Ashcroft, A mutation causing increased KATP channel activity leads to reduced anxiety in mice, Physiol. Behav. 129 (2014) 79-84.

[33] L. Gutknecht, S. Popp, J. Waider, F.M. Sommerlandt, C. Goppner, A. Post, A. Reif, D. van den Hove, T. Strekalova, A. Schmitt, M.B. Colavarsigmao, C. Sommer, R. Palme, K.P. Lesch, Interaction of brain 5-HT synthesis deficiency, chronic stress and sex differentially impact emotional behavior in Tph2 knockout mice, Psychopharmacology (Berl.) 232 (14) (2015) 2429-2441.

[34] F. Vahid-Ansari, M. Daigle, M.C. Manzini, K.F. Tanaka, R. Hen, S.D. Geddes, J.C. Beique, J. James, Z. Merali, P.R. Albert, Abrogated Freud-1/Cc2d1a repression of 5-HT1A autoreceptors induces fluoxetine-resistant anxiety/depression-like behavior, J. Neurosci. 37 (49) (2017) 11967-11978.

[35] O. Lopatina, T. Yoshihara, T. Nishimura, J. Zhong, S. Akther, A.A. Fakhrul, M. Liang, C. Higashida, K. Sumi, K. Furuhara, Y. Inahata, J.J. Huang, K. Koizumi, S. Yokoyama, T. Tsuji, Y. Petugina, A. Sumarokov, A.B. Salmina, K. Hashida, Y. Kitao, O. Hori, M. Asano, Y. Kitamura, T. Kozaka, K. Shiba, F. Zhong, M.J. Xie, M. Sato, K. Ishihara, H. Higashida, Anxiety- and depression-like behavior in mice 
lacking the CD157/BST1 gene, a risk factor for Parkinson's disease, Front. Behav. Neurosci. 8 (2014) 133

[36] C.J. Barnard, N. Luo, Acquisition of dominance status affects maze learning in mice, Behav. Processes 60 (1) (2002) 53-59.

[37] F. Boyer, J.L. Dreyer, The role of gamma-synuclein in cocaine-induced behaviour in rats, Eur. J. Neurosci. 27 (11) (2008) 2938-2951.

[38] A. Bahi, F. Boyer, G. Bussard, J.L. Dreyer, Silencing dopamine D3-receptors in the nucleus accumbens shell in vivo induces changes in cocaine-induced hyperlocomotion, Eur. J. Neurosci. 21 (12) (2005) 3415-3426.

[39] A. Bahi, F. Boyer, C. Gumy, T. Kafri, J.L. Dreyer, In vivo gene delivery of urokinasetype plasminogen activator with regulatable lentivirus induces behavioural changes in chronic cocaine administration, Eur. J. Neurosci. 20 (12) (2004) 3473-3488.

[40] A. Bahi, F. Boyer, M. Kolira, J.L. Dreyer, In vivo gene silencing of CD81 by lentiviral expression of small interference RNAs suppresses cocaine-induced behaviour, J. Neurochem. 92 (5) (2005) 1243-1255.

[41] A. Bahi, The oxytocin receptor impairs ethanol reward in mice, Physiol. Behav. 139 (2015) 321-327.

[42] A. Bahi, S. Al Mansouri, E. Al Maamari, Nucleus accumbens lentiviral-mediated gain of function of the oxytocin receptor regulates anxiety- and ethanol-related behaviors in adult mice, Physiol. Behav. 164 (Pt A) (2016) 249-258.

[43] A. Bahi, J.L. Dreyer, Involvement of nucleus accumbens dopamine D1 receptors in ethanol drinking, ethanol-induced conditioned place preference, and ethanol-induced psychomotor sensitization in mice, Psychopharmacology (Berl.) 222 (1) (2012) 141-153.

[44] K.B.J. Franklin, G. Paxinos, The Mouse Brain in Stereotaxic Coordinates, New York (1996).

[45] A. Bahi, Individual differences in elevated plus-maze exploration predicted higher ethanol consumption and preference in outbred mice, Pharmacol. Biochem. Behav. 105 (2013) 83-88.

[46] A. Bahi, Decreased anxiety, voluntary ethanol intake and ethanol-induced CPP acquisition following activation of the metabotropic glutamate receptor 8 "mGluR8", Pharmacol. Biochem. Behav. 155 (2017) 32-42.

[47] A. Bahi, S. Al Mansouri, E. Al Memari, M. Al Ameri, S.M. Nurulain, S. Ojha, BetaCaryophyllene, a CB2 receptor agonist produces multiple behavioral changes relevant to anxiety and depression in mice, Physiol. Behav. 135 (2014) 119-124.

[48] S. Pellow, P. Chopin, S.E. File, M. Briley, Validation of open:closed arm entries in an elevated plus-maze as a measure of anxiety in the rat, J. Neurosci. Methods 14 (3) (1985) 149-167.

[49] A. Bahi, Environmental enrichment reduces chronic psychosocial stress-induced anxiety and ethanol-related behaviors in mice, Prog. Neuropsychopharmacol. Biol. Psychiatry 77 (2017) 65-74.

[50] A. Bahi, J.S. Schwed, M. Walter, H. Stark, B. Sadek, Anxiolytic and antidepressantlike activities of the novel and potent non-imidazole histamine $\mathrm{H}(3)$ receptor antagonist ST-1283, Drug Des. Dev. Ther. 8 (2014) 627-637.

[51] G.S. Wable, J.Y. Min, Y.W. Chen, C. Aoki, Anxiety is correlated with running in adolescent female mice undergoing activity-based anorexia, Behav. Neurosci. 129 (2) (2015) 170-182.

[52] T. Okonogi, R. Nakayama, T. Sasaki, Y. Ikegaya, Characterization of peripheral activity states and cortical local field potentials of mice in an elevated plus maze test, Front. Behav. Neurosci. 12 (2018) 62.

[53] J. Crawley, F.K. Goodwin, Preliminary report of a simple animal behavior model fo the anxiolytic effects of benzodiazepines, Pharmacol. Biochem. Behav. 13 (2) (1980) 167-170.

[54] I. Heinla, J. Ahloren, E. Vasar, V. Voikar, Behavioural characterization of C57BL/6N and BALB/c female mice in social home cage-effect of mixed housing in complex environment, Physiol. Behav. 188 (2018) 32-41.

[55] S.K. Rouzer, J.M. Cole, J.M. Johnson, E.I. Varlinskaya, M.R. Diaz, Moderate maternal alcohol exposure on gestational day 12 impacts anxiety-like behavior in offspring, Front. Behav. Neurosci. 11 (2017) 183.

[56] R.R. Gelineau, N.L. Arruda, J.A. Hicks, I. Monteiro De Pina, A. Hatzidis, J.A. Seggio The behavioral and physiological effects of high-fat diet and alcohol consumption: sex differences in C57BL6/J mice, Brain Behav. 7 (6) (2017) e00708.

[57] A. Bahi, V. Chandrasekar, J.L. Dreyer, Selective lentiviral-mediated suppression of microRNA124a in the hippocampus evokes antidepressants-like effects in rats, Psychoneuroendocrinology 46 (2014) 78-87.

[58] R.D. Porsolt, A. Bertin, M. Jalfre, Behavioral despair in mice: a primary screening test for antidepressants, Arch. Int. Pharmacodyn. Ther. 229 (2) (1977) 327-336.

[59] A. Bahi, J.L. Dreyer, Hippocampus-specific deletion of tissue plasminogen activator "tPA" in adult mice impairs depression- and anxiety-like behaviors, Eur. Neuropsychopharmacol. 22 (9) (2012) 672-682.

[60] K. Hirani, R.T. Khisti, C.T. Chopde, Behavioral action of ethanol in Porsolt's forced swim test: modulation by 3 alpha-hydroxy-5 alpha-pregnan-20-one, Neuropharmacology 43 (8) (2002) 1339-1350.

[61] C. Perez-Garcia, L. Morales, M.V. Cano, I. Sancho, L.F. Alguacil, Effects of histamine $\mathrm{H} 3$ receptor ligands in experimental models of anxiety and depression, Psychopharmacology (Berl.) 142 (2) (1999) 215-220.

[62] A. Dhir, S.K. Kulkarni, Risperidone, an atypical antipsychotic enhances the antidepressant-like effect of venlafaxine or fluoxetine: possible involvement of alpha-2 adrenergic receptors, Neurosci. Lett. 445 (1) (2008) 83-88.

[63] K. Socala, D. Nieoczym, E. Wyska, E. Poleszak, P. Wlaz, Sildenafil, a phosphodiesterase type 5 inhibitor, reduces antidepressant-like activity of paroxetine in the forced swim test in mice, Pharmacol. Rep. 64 (5) (2012) 1259-1266.

[64] A. Djillani, M. Pietri, S. Moreno, C. Heurteaux, J. Mazella, M. Borsotto, Shortened spadin analogs display better TREK-1 inhibition, in vivo stability and antidepressant activity, Front. Pharmacol. 8 (2017) 643.

[65] J.A. Gordon, R. Hen, Genetic approaches to the study of anxiety, Annu. Rev.
Neurosci. 27 (2004) 193-222.

[66] N.M. Richtand, J.R. Kelsoe, D.S. Segal, R. Kuczenski, Regional quantification of dopamine transporter mRNA in rat brain using a ribonuclease protection assay, Neurosci. Lett. 200 (2) (1995) 73-76.

[67] B.J. Ciliax, G.W. Drash, J.K. Staley, S. Haber, C.J. Mobley, G.W. Miller, E.J. Mufson, D.C. Mash, A.I. Levey, Immunocytochemical localization of the dopamine transporter in human brain, J. Comp. Neurol. 409 (1) (1999) 38-56.

[68] A.C. Carpenter, T.P. Saborido, G.D. Stanwood, Development of hyperactivity and anxiety responses in dopamine transporter-deficient mice, Dev. Neurosci. 34 (2-3) (2012) 250-257.

[69] S. Weiss, M. Nosten-Bertrand, J.M. McIntosh, B. Giros, M.P. Martres, Nicotine improves cognitive deficits of dopamine transporter knockout mice without long-term tolerance, Neuropsychopharmacology 32 (12) (2007) 2465-2478.

[70] J. Innos, E. Leidmaa, M.A. Philips, S. Sutt, A. Alttoa, J. Harro, S. Koks, E. Vasar, Lsamp $(-) /(-)$ mice display lower sensitivity to amphetamine and have elevated 5-HT turnover, Biochem. Biophys. Res. Commun. 430 (1) (2013) 413-418.

[71] C. Spielewoy, C. Roubert, M. Hamon, M. Nosten-Bertrand, C. Betancur, B. Giros, Behavioural disturbances associated with hyperdopaminergia in dopamine-transporter knockout mice, Behav. Pharmacol. 11 (3-4) (2000) 279-290.

[72] B. Giros, M. Jaber, S.R. Jones, R.M. Wightman, M.G. Caron, Hyperlocomotion and indifference to cocaine and amphetamine in mice lacking the dopamine transporter, Nature 379 (6566) (1996) 606-612.

[73] V.M. Pogorelov, R.M. Rodriguiz, M.L. Insco, M.G. Caron, W.C. Wetsel, Novelty seeking and stereotypic activation of behavior in mice with disruption of the Dat1 gene, Neuropsychopharmacology 30 (10) (2005) 1818-1831.

[74] R. Carey, J. Gui, A simple and reliable method for the positive identification of pavlovian conditioned cocaine effects in open-field behavior, J. Neurosci. Methods 73 (1) (1997) 1-8.

[75] J.T. Yorgason, R.A. Espana, J.K. Konstantopoulos, J.L. Weiner, S.R. Jones, Enduring increases in anxiety-like behavior and rapid nucleus accumbens dopamine signaling in socially isolated rats, Eur. J. Neurosci. 37 (6) (2013) 1022-1031.

[76] A.M. Garcia, R. Martinez, M.L. Brandao, S. Morato, Effects of apomorphine on rat behavior in the elevated plus-maze, Physiol. Behav. 85 (4) (2005) 440-447.

[77] M. Bananej, A. Karimi-Sori, M.R. Zarrindast, S. Ahmadi, D1 and D2 dopaminergic systems in the rat basolateral amygdala are involved in anxiogenic-like effects induced by histamine, J. Psychopharmacol. 26 (4) (2012) 564-574.

[78] M. Perez de la Mora, A. Gallegos-Cari, M. Crespo-Ramirez, D. Marcellino, A.C. Hansson, K. Fuxe, Distribution of dopamine D(2)-like receptors in the rat amygdala and their role in the modulation of unconditioned fear and anxiety, Neuroscience 201 (2012) 252-266.

[79] A.K. Dutta, B. Ghosh, S. Biswas, M.E. Reith, D-161, a novel pyran-based triple monoamine transporter blocker: behavioral pharmacological evidence for antidepressant-like action, Eur. J. Pharmacol. 589 (1-3) (2008) 73-79.

[80] D.J. David, C.E. Renard, P. Jolliet, M. Hascoet, M. Bourin, Antidepressant-like effects in various mice strains in the forced swimming test, Psychopharmacology (Berl.) 166 (4) (2003) 373-382.

[81] J.A. Ascher, J.O. Cole, J.N. Colin, J.P. Feighner, R.M. Ferris, H.C. Fibiger, R.N. Golden, P. Martin, W.Z. Potter, E. Richelson, et al., Bupropion: a review of its mechanism of antidepressant activity, J. Clin. Psychiatry 56 (9) (1995) 395-401.

[82] M.C. Hsiao, K.J. Lin, C.Y. Liu, D.B. Schatz, The interaction between dopamine transporter function, gender differences, and possible laterality in depression, Psychiatry Res. 211 (1) (2013) 72-77.

[83] B.J. Caldarone, N.E. Paterson, J. Zhou, D. Brunner, A.P. Kozikowski, K.G. Westphal, G.A. Korte-Bouws, J. Prins, S.M. Korte, B. Olivier, A. Ghavami, The novel triple reuptake inhibitor JZAD-IV-22 exhibits an antidepressant pharmacological profile without locomotor stimulant or sensitization properties, J. Pharmacol. Exp. Ther. 335 (3) (2010) 762-770.

[84] B.J. Caldarone, N.E. Paterson, J. Zhou, D. Brunner, A.P. Kozikowski, K. G. Westphal, G.A. Korte-Bouws, J. Prins, S.M. Korte, B. Olivier, A. Ghavami, The novel triple reuptake inhibitor JZAD-IV-22 exhibits an antidepressant pharmacological profile without locomotor stimulant or sensitization properties, J. Pharmacol. Exp. Ther. 335 (3) (2011) 762-770.

[85] A.K. Dutta, S. Santra, H. Sharma, C. Voshavar, L. Xu, O. Mabrouk, T. Antonio, M.E. Reith, Pharmacological and behavioral characterization of D-473, an orally active triple reuptake inhibitor targeting dopamine, serotonin and norepinephrine transporters, PLoS One 9 (11) (2014) e113420.

[86] M.P. Dandekar, D. Luse, C. Hoffmann, P. Cotton, T. Peery, C. Ruiz, C. Hussey, V.V. Giridharan, J.C. Soares, J. Quevedo, A.J. Fenoy, Increased dopamine receptor expression and anti-depressant response following deep brain stimulation of the medial forebrain bundle, J. Affect. Disord. 217 (2017) 80-88.

[87] M.T. Perona, S. Waters, F.S. Hall, I. Sora, K.P. Lesch, D.L. Murphy, M. Caron, G.R. Uhl, Animal models of depression in dopamine, serotonin, and norepinephrine transporter knockout mice: prominent effects of dopamine transporter deletions, Behav. Pharmacol. 19 (5-6) (2008) 566-574.

[88] K.M. Tye, J.J. Mirzabekov, M.R. Warden, E.A. Ferenczi, H.C. Tsai, J. Finkelstein, S.Y. Kim, A. Adhikari, K.R. Thompson, A.S. Andalman, L.A. Gunaydin, I.B. Witten, K. Deisseroth, Dopamine neurons modulate neural encoding and expression of depression-related behaviour, Nature 493 (7433) (2013) 537-541.

[89] R.A. Wise, Dopamine and reward: the anhedonia hypothesis 30 years on, Neurotoxicol. Res. 14 (2-3) (2008) 169-183.

[90] P.S. D'Aquila, M. Collu, G.L. Gessa, G. Serra, The role of dopamine in the mechanism of action of antidepressant drugs, Eur. J. Pharmacol. 405 (1-3) (2000) 365-373.

[91] A. Sato, O. Nakagawasai, K. Tan-No, H. Onogi, F. Niijima, T. Tadano, Effect of nonselective dopaminergic receptor agonist on disrupted maternal behavior in olfactory bulbectomized mice, Behav. Brain Res. 210 (2) (2010) 251-256. 
[92] D.J. Brunswick, J.D. Amsterdam, P.D. Mozley, A. Newberg, Greater availability of brain dopamine transporters in major depression shown by [99m Tc]TRODAT-1 SPECT imaging, Am. J. Psychiatry 160 (10) (2003) 1836-1841.

[93] T. Laasonen-Balk, J. Kuikka, H. Viinamaki, M. Husso-Saastamoinen, J. Lehtonen, J. Tiihonen, Striatal dopamine transporter density in major depression, Psychopharmacology (Berl.) 144 (3) (1999) 282-285.

[94] A. Neumeister, M. Willeit, N. Praschak-Rieder, S. Asenbaum, J. Stastny, E. Hilger, W. Pirker, A. Konstantinidis, S. Kasper, Dopamine transporter availability in symptomatic depressed patients with seasonal affective disorder and healthy controls, Psychol. Med. 31 (8) (2001) 1467-1473.

[95] D. Weintraub, A.B. Newberg, M.S. Cary, A.D. Siderowf, P.J. Moberg, G. KleinerFisman, J.E. Duda, M.B. Stern, D. Mozley, I.R. Katz, Striatal dopamine transporter imaging correlates with anxiety and depression symptoms in Parkinson's disease, J. Nucl. Med. 46 (2) (2005) 227-232.

[96] E. Zoons, M.A.J. Tijssen, Y.E.M. Dreissen, J.D. Speelman, M. Smit, J. Booij, The relationship between the dopaminergic system and depressive symptoms in cervical dystonia, Eur. J. Nucl. Med. Mol. Imaging 44 (8) (2017) 1375-1382. 